\title{
Modifying effect of metabotype on diet-diabetes associations
}

\author{
Anna Riedl ${ }^{1,2,3} \cdot$ Nina Wawro ${ }^{1,2,3} \cdot$ Christian Gieger $^{3,4,5} \cdot$ Christa Meisinger $^{1,2,3,4} \cdot$ Annette Peters ${ }^{3,4}$. \\ Wolfgang Rathmann ${ }^{3,6}$. Wolfgang Koenig ${ }^{7,8,9} \cdot$ Konstantin Strauch $^{10,11} \cdot$ Anne S. Quante ${ }^{10,11,12}$. Barbara Thorand ${ }^{3,4}$. \\ Cornelia Huth $^{3,4} \cdot$ Hannelore Daniel ${ }^{13} \cdot$ Hans Hauner $^{14,15,16} \cdot$ Jakob Linseisen $^{1,2,15}$
}

Received: 3 September 2018 / Accepted: 5 May 2019 / Published online: 14 May 2019

(c) The Author(s) 2019

\begin{abstract}
Purpose Inter-individual metabolic differences may be a reason for previously inconsistent results in diet-diabetes associations. We aimed to investigate associations between dietary intake and diabetes for metabolically homogeneous subgroups ('metabotypes') in a large cross-sectional study.

Methods We used data of 1517 adults aged 38-87 years from the German population-based KORA FF4 study (2013/2014). Dietary intake was estimated based on the combination of a food frequency questionnaire and multiple 24-h food lists. Glucose tolerance status was classified based on an oral glucose tolerance test in participants without a previous diabetes diagnosis using American Diabetes Association criteria. Logistic regression was applied to examine the associations between dietary intake and diabetes for two distinct metabotypes, which were identified based on 16 biochemical and anthropometric parameters.

Results A low intake of fruits and a high intake of total meat, processed meat and sugar-sweetened beverages (SSB) were significantly associated with diabetes in the total study population. Stratified by metabotype, associations with diabetes remained significant for intake of total meat (OR 1.67, 95\% CI 1.04-2.67) and processed meat (OR 2.23, 95\% CI 1.24-4.04) in the metabotypes with rather favorable metabolic characteristics, and for intake of fruits (OR $0.83,95 \%$ CI $0.68-0.99)$ and SSB (OR:1.21, 95\% CI 1.09-1.35) in the more unfavorable metabotype. However, only the association between SSB intake and diabetes differed significantly by metabotype $(p$ value for interaction $=0.01$ ).

Conclusions Our findings suggest an influence of metabolic characteristics on diet-diabetes associations, which may help to explain inconsistent previous results. The causality of the observed associations needs to be confirmed in prospective and intervention studies.
\end{abstract}

Keywords Diabetes $\cdot$ Diet $\cdot$ enable-Cluster $\cdot$ Metabolic phenotype $\cdot$ Metabotype

\section{Introduction}

Type 2 diabetes mellitus (T2DM) with its adverse health consequences for individuals and its financial burden on healthcare systems is an important public health issue worldwide [1, 2]. In Germany, the prevalence of known T2DM was $8.5 \%$ in 2009 and $9.5 \%$ in 2015 , and it is expected to rise further due to an ageing population with an increase in

Electronic supplementary material The online version of this article (https://doi.org/10.1007/s00394-019-01988-5) contains supplementary material, which is available to authorized users.

Anna Riedl

anna.riedl@helmholtz-muenchen.de

Extended author information available on the last page of the article unhealthy lifestyle $[1,3]$. It has to be assumed that the actual prevalence of T2DM is even higher due to a large number of undiagnosed individuals $[4,5]$.

Changes in lifestyle, for example in dietary behavior, may prevent or delay the development of T2DM [6-8]. However, previous studies investigating the impact of food on the risk of T2DM have shown inconsistent results $[9,10]$.

It is well established that the variability of metabolic characteristics between individuals leads to differences in the response to dietary factors [11-15]. This could be a reason why associations of food groups and nutrients with T2DM are often weak or even different between studies. The identification of metabolically homogeneous subgroups of the population, so-called metabotypes or metabolic phenotypes [16-21], has already been performed several times [16, 
22, 23], and may help to better understand the inconsistency in diet-T2DM associations across studies. Furthermore, this may be relevant in diabetes prevention for the development of targeted dietary recommendations at the metabotype subgroup level, which may be more effective than general dietary advice $[11,14,16,24,25]$.

Therefore, we aimed (1) to identify distinct metabotypes and (2) to investigate the cross-sectional associations of intake of several food groups and nutrients with T2DM stratified by metabotype subgroup in the large populationbased Cooperative Health Research in the Region of Augsburg (KORA) FF4 study.

\section{Methods}

\section{Study population}

Analyses were performed on data from the populationbased KORA FF4 (2013/2014) study, the second followup of the KORA S4 health survey conducted in the region of Augsburg in Southern Germany between 1999 and 2001 [26]. In brief, of the 4261 participants included in S4, 2279 individuals also participated in the 14-year follow-up FF4 study. Detailed information on the participation response has been given elsewhere [27]. All individuals answered selfadministered questionnaires, and participated in a standardized physical examination as well as in a computer-assisted face-to-face interview conducted by trained investigators at the study center. A detailed description has been provided previously [5].

\section{Ethical standards}

All participants gave their written informed consent, and the study was approved by the Ethics Committee of the Bavarian Chamber of Physicians and conducted in accordance with the Declaration of Helsinki.

\section{Assessment of glucose tolerance status}

Prevalent diabetes was defined by either current intake of antidiabetic medication or a self-reported diagnosis, both validated with the respective treating physician. All participants without previously known diabetes took part in a standard oral glucose tolerance test (OGTT) and their glucose tolerance status was classified according to the 2003 American Diabetes Association (ADA) diagnostic criteria [28]. Further details have been outlined elsewhere [29]. An OGTT value of $\geq 7.0 \mathrm{mmol} / \mathrm{L}$ fasting or $\geq 11.1 \mathrm{mmol} / \mathrm{L}$ 2-h glucose was defined as undetected diabetes mellitus (UDM), also called screen-detected diabetes. Participants with isolated impaired fasting glucose (IFG 5.6-6.9 mmol/L fasting glucose), isolated impaired glucose tolerance (IGT 7.8-11.0 mmol/L 2-h glucose) or combined IFG/IGT were classified as prediabetic. Individuals with fasting glucose levels $<5.6 \mathrm{mmol} / \mathrm{L}$ and 2-h glucose levels $<7.8 \mathrm{mmol} / \mathrm{L}$ were classified as normal glucose tolerant (NGT).

\section{Assessment of dietary intake}

Dietary intake was assessed in 1602 KORA FF4 participants with up to three 24-h food lists [30] and a food frequency questionnaire. Combining this information, the usual dietary intake was estimated in an advanced blended two-step approach, which follows the idea of the National Cancer Institute (NCI) method and the Multiple Source Method (MSM) [31, 32] to separate the calculation of consumption amount and consumption probability. The consumption probability and the consumption amount on consumption days were estimated separately with models both including the same covariates to link the two parts. Then, the usual dietary intake of all food items was calculated for each participant by multiplying the consumption probability of a certain food item by the usual consumption amount on a consumption day. The food groups were categorized according to the European Prospective Investigation into Cancer and Nutrition (EPIC)-Soft classification system [33] and nutrients were derived using the National Nutrient Database (Bundeslebensmittelschlüssel BLS 3.02). For the analysis, we selected the 17 following food groups and nutrients in $\mathrm{g} / \mathrm{d}$ associated with T2DM in the literature [9, 10, 34, 35]: fruits, vegetables, potatoes, total meat, red meat (beef and pork), poultry, processed meat, eggs, total dairy, milk, yogurt, cheese, coffee, fruit and vegetable juice, sugar-sweetened beverages (SSB), alcohol and fiber.

\section{Assessment of covariates}

The selection of covariates was based on theoretical considerations and the existing literature on diet and diabetes [9]. These included age (years), sex (reference $=$ male), energy intake ( $\mathrm{kcal} /$ day), waist circumference $(\mathrm{cm})$, family history of diabetes [yes, no (= reference), do not know], physical activity [active in summer and in winter and active for $\geq 1 \mathrm{~h}$ per week in at least one season, inactive (= reference)], smoking status [never (= reference), former, current], hypertension $[\geq 140 / 90 \mathrm{mmHg}$ or antihypertensive medication given that the participants were aware of having hypertension; yes, no $(=$ reference $)]$ and education $[<10$ years (= reference), 10 to $<13$ years, $\geq 13$ years, in accordance with the German education system]. Waist circumference and blood pressure were measured at the study center under standardized conditions by trained staff. All other covariates were assessed during a standardized personalized computerassisted interview or via a self-administered questionnaire. 


\section{Statistical analysis}

We performed all statistical analyses using the statistical software package RStudio version 1.0.136 that uses $\mathrm{R}$ version 3.2.2 (R Development Core Team, 2010, http://www.rproject.org). $p$ values of $<0.05$ were considered statistically significant.

\section{Identification of metabotypes}

The metabotypes were identified in KORA FF4 analogous to Riedl et al. [23] in KORA F4. Of the 34 originally used anthropometric and fasting biochemical blood parameters in KORA F4, a subset of 16 parameters was also available in KORA FF4 for the definition of metabotypes. These included body mass index (BMI), and the following blood biomarkers: glucose, total cholesterol, high density lipoprotein cholesterol, total cholesterol/high density lipoprotein cholesterol ratio, low-density lipoprotein cholesterol, glycated hemoglobin, uric acid, triglycerides, leukocytes, gamma-glutamyltransferase, glutamate-pyruvate transaminase, glutamate-oxaloacetate transaminase, alkaline phosphatase, high-sensitivity C-reactive protein and insulin.

In the preprocessing step, the KORA FF4 study population ( $n=2279$ ) was reduced to 2218 participants by excluding 54 participants who did not fast for at least $8 \mathrm{~h}$ before blood collection and by excluding 7 participants with more than $10 \%$ missing values of all clustering variables listed above. The remaining missing values in the clustering variables were imputed using the R package "mice" (multivariate imputation by chained equations) version 2.25 [36] generating five complete data sets with ten iterations each. All biochemical and anthropometric parameters were $z$-standardized prior to clustering. Subsequently, the 2218 FF4 participants were divided into three clusters using the k-means cluster algorithm of the R package "miclust" (multiple imputation in cluster analysis) version 1.2.5 [37] based on all 16 biochemical and anthropometric parameters available in this study. A detailed metabolic characterization of these clusters representing metabotypes is provided in the Online Resource (Supplemental Table 1). Further details on the identification procedure of metabotypes are given elsewhere [23].

\section{Analysis of associations between dietary intake and diabetes}

Of the total 2218 FF4 participants with metabotype information, those with type 1 diabetes mellitus $(n=4)$, unclear glucose tolerance status $(n=67)$ or missing information on dietary intake $(n=628)$ or covariate data $(n=2)$ were excluded from the analyses resulting in a final sample size of 1517 participants. All food groups were rescaled for $50 \mathrm{~g} /$ day increments. Among the investigated nutrients, fiber was rescaled to $10 \mathrm{~g} /$ day and alcohol intake was classified by sex in accordance with the reference values of the German Nutrition Society (Deutsche Gesellschaft für Ernährung) as low ( $<5 \mathrm{~g} /$ day for men and $<2 \mathrm{~g} /$ day for women), moderate ( 5 to $<20 \mathrm{~g} /$ day for men and 2 to $<10 \mathrm{~g} /$ day for women) or high ( $\geq 20 \mathrm{~g} /$ day for men and $\geq 10 \mathrm{~g} /$ day for women) [38]. Due to the low diabetes prevalence in metabotype clusters 1 and 2 (see Table 1), these groups were combined and analyzed together in comparison to cluster 3 .

To examine the cross-sectional associations between dietary intake and diabetes dichotomized in NGT/prediabetes (= reference) and UDM/prevalent T2DM, binary logistic regression was performed. For each of the dietary intake variables, two models with different sets of covariates were fitted: the basic model was adjusted for age, sex and energy intake; the fully adjusted model was additionally adjusted for waist circumference, family history of diabetes, physical activity, smoking, education, hypertension, and metabotype. Thus, the respective models differed only in the dietary intake variable used, but included the same sample size and covariates. All analyses were performed for the total study population and stratified by metabotype subgroup.

Likelihood ratio tests were used to detect possible interaction effects between metabotypes and the respective dietary intake variables in the fully adjusted model. Significant results indicated differences in diet-diabetes associations between metabotype subgroups. A flow chart showing the overall analysis strategy is provided in the Online Resource (Supplemental Fig. 1).

As a sensitivity analysis, we fitted intermediate adjusted models removing the covariates hypertension and waist circumference from the fully adjusted models, as these are rather intermediary/mediating variables than real confounders in diet-diabetes associations. In another sensitivity analysis, we restricted the study population to adults aged $\geq 60$ years to investigate age-specific effects.

\section{Results}

The number of individuals at each stage of our analysis is shown in the flow chart in Supplemental Fig. 1 provided in the Online Resource, leaving a final study population of 1517 individuals for the analysis of diet-diabetes associations.

Table 1 presents the characteristics of the total study population and for each of the three metabotypes identified in KORA FF4. The total study population consists of approximately equal proportions of men and women with an age range of 38-87 years. Of 1517 participants, 777 (51.2\%) had NGT, 539 (35.5\%) had prediabetes, 64 (4.2\%) had UDM and 137 (9.0\%) had prevalent T2DM. By metabotyping, 678 participants (about 45\%) were grouped into cluster 1, 539 
Table 1 Demographic baseline characteristics of the total study population and across the three metabotype clusters, KORA FF4 study

\begin{tabular}{|c|c|c|c|c|}
\hline & \multirow{3}{*}{$\begin{array}{l}\text { Total } \\
N=1517\end{array}$} & \multicolumn{3}{|l|}{ Metabotypes } \\
\hline & & Cluster 1 & Cluster 2 & Cluster 3 \\
\hline & & $N=678$ & $N=539$ & $N=300$ \\
\hline \multicolumn{5}{|l|}{ Glucose tolerance status } \\
\hline NGT & 777 (51.2) & 485 (71.5) & $254(47.1)$ & $38(12.7)$ \\
\hline Prediabetes & $539(35.5)$ & $160(23.6)$ & $244(45.3)$ & $135(45.0)$ \\
\hline UDM & $64(4.2)$ & $12(1.8)$ & $23(4.3)$ & $29(9.7)$ \\
\hline Prevalent T2DM & $137(9.0)$ & $21(3.1)$ & $18(3.3)$ & $98(32.7)$ \\
\hline \multicolumn{5}{|l|}{ Sex } \\
\hline Men & $743(49.0)$ & 228 (33.6) & $313(58.1)$ & $202(67.3)$ \\
\hline Women & $774(51.0)$ & $450(66.4)$ & $226(41.9)$ & $98(32.7)$ \\
\hline \multicolumn{5}{|l|}{ Age (years) } \\
\hline Median (25th, 75th) & $60.0(50.0,69.0)$ & $55.0(47.0,66.0)$ & $61.0(52.0,69.0)$ & $65.0(56.8,73.0)$ \\
\hline \multicolumn{5}{|l|}{ Education (years) } \\
\hline$<10$ & $76(5.0)$ & $25(3.7)$ & $33(6.1)$ & $18(6.0)$ \\
\hline 10 to $<13$ & $885(58.3)$ & $365(53.8)$ & $325(60.3)$ & $195(65.0)$ \\
\hline$\geq 13$ & $556(36.7)$ & $288(42.5)$ & $181(33.6)$ & $87(29.0)$ \\
\hline \multicolumn{5}{|l|}{ BMI $\left(\mathrm{kg} \mathrm{m}^{-2}\right)$} \\
\hline Median (25th, 75th) & $26.9(24.3,30.3)$ & $24.6(22.7,26.8)$ & $27.8(25.6,30.4)$ & $31.4(28.6,35.4)$ \\
\hline Underweight & $6(0.4)$ & $6(0.9)$ & $0(0.0)$ & $0(0.0)$ \\
\hline Normal & $483(31.8)$ & $361(53.2)$ & $103(19.1)$ & $19(6.3)$ \\
\hline Overweight & $627(41.3)$ & $252(37.2)$ & $281(52.1)$ & $94(31.3)$ \\
\hline Obese & $401(26.4)$ & $59(8.7)$ & $155(28.8)$ & $187(62.3)$ \\
\hline \multicolumn{5}{|c|}{ Waist circumference $(\mathrm{cm})$} \\
\hline Median (25th, 75th) & $96.3(85.7,105.4)$ & $86.9(79.1,96.1)$ & $98.9(92.3,105.3)$ & $109.7(102.3,117.4)$ \\
\hline \multicolumn{5}{|l|}{ Physical activity } \\
\hline Inactive & $587(38.7)$ & $209(30.8)$ & $205(38.0)$ & $173(57.7)$ \\
\hline Active & $930(61.3)$ & $469(69.2)$ & $334(62.0)$ & $127(42.3)$ \\
\hline \multicolumn{5}{|l|}{ Smoking status } \\
\hline Nonsmoker & $637(42.0)$ & $304(44.8)$ & $224(41.6)$ & $109(36.3)$ \\
\hline Ex-smoker & $675(44.5)$ & $281(41.4)$ & $237(44.0)$ & $157(52.3)$ \\
\hline Smoker & $205(13.5)$ & $93(13.7)$ & $78(14.5)$ & $34(11.3)$ \\
\hline \multicolumn{5}{|c|}{ Family history of diabetes } \\
\hline Yes & $496(32.7)$ & $200(29.5)$ & $179(33.2)$ & $117(39.0)$ \\
\hline No & 879 (57.9) & $435(64.2)$ & $302(56.0)$ & $142(47.3)$ \\
\hline Do not know & $142(9.4)$ & $43(6.3)$ & $58(10.8)$ & $41(13.7)$ \\
\hline \multicolumn{5}{|l|}{ Hypertension } \\
\hline Yes & $588(38.8)$ & $174(25.7)$ & $210(39.0)$ & $204(68.0)$ \\
\hline No & $929(61.2)$ & $504(74.3)$ & $329(61.0)$ & $96(32.0)$ \\
\hline
\end{tabular}

Median (25th, 75th percentile) for continuous variables and $n$ (column \%) for categorical variables $B M I$ body mass index, KORA Cooperative Health Research in the Region of Augsburg, NGT normal glucose tolerance, $T 2 D M$ type 2 diabetes mellitus, $U D M$ undetected diabetes mellitus participants (about 36\%) into cluster 2, and 300 participants (about 20\%) into cluster 3 . The proportion of participants with UDM and prevalent T2DM was higher in cluster 3 compared to cluster 2 and cluster 1, respectively (UDM: $9.7 \%$ vs. $4.3 \%$ vs. $1.8 \%$; prevalent T2DM: $32.7 \%$ vs. $3.3 \%$ vs. $3.1 \%$ ). Cluster 3 showed the highest proportions of men, individuals with a positive family history of diabetes and hypertension. At the same time, cluster 3 showed the lowest percentages of highly educated and physically active participants as well as current smokers. Participants of cluster 3 were further characterized by the highest median age, BMI and waist circumference.

Table 2 shows the median usual dietary intake of participants in the combined clusters 1 and 2 and of participants in cluster 3 , in total and according to glucose tolerance status (NGT/prediabetes and UDM/prevalent T2DM). The 
Table 2 Usual dietary intake of the study population by metabotype subgroup for NGT/prediabetes and UDM/prevalent T2DM, KORA FF4 study

\begin{tabular}{|c|c|c|c|}
\hline & Total & NGT/prediabetes & $\begin{array}{l}\text { UDM/prevalent } \\
\text { T2DM }\end{array}$ \\
\hline Total & $N=1517$ & $N=1316$ & $N=201$ \\
\hline Cluster 1/cluster 2 & $N=1217$ & $N=1143$ & $N=74$ \\
\hline \multirow[t]{2}{*}{ Cluster 3} & $N=300$ & $N=173$ & $N=127$ \\
\hline & Median $(25 \%, 75 \%)$ & Median $(25 \%, 75 \%)$ & Median $(25 \%, 75 \%)$ \\
\hline \multicolumn{4}{|l|}{ Food item } \\
\hline \multicolumn{4}{|l|}{ Fruits (g/day) } \\
\hline Cluster 1/cluster 2 & $145(92,206)$ & $145(91,205)$ & $146(122,215)$ \\
\hline Cluster 3 & $148(90,214)$ & $147(89,209)$ & $149(96,214)$ \\
\hline \multicolumn{4}{|l|}{ Vegetables (g/day) } \\
\hline Cluster 1/cluster 2 & $168(137,210)$ & $168(137,211)$ & $165(132,195)$ \\
\hline Cluster 3 & $149(121,184)$ & $149(122,184)$ & $147(121,185)$ \\
\hline \multicolumn{4}{|l|}{ Potatoes (g/day) } \\
\hline Cluster 1/cluster 2 & $55(44,70)$ & $54(44,69)$ & $64(53,84)$ \\
\hline Cluster 3 & $59(48,78)$ & $57(46,75)$ & $63(50,82)$ \\
\hline \multicolumn{4}{|l|}{ Total meat (g/day) } \\
\hline Cluster 1/cluster 2 & $102(81,134)$ & $102(80,133)$ & $115(88,141)$ \\
\hline Cluster 3 & $136(102,161)$ & $140(104,167)$ & $133(102,160)$ \\
\hline \multicolumn{4}{|l|}{ Red meat (g/day) } \\
\hline Cluster 1/cluster 2 & $25(19,33)$ & $25(19,33)$ & $28(19,36)$ \\
\hline Cluster 3 & $30(22,40)$ & $29(23,40)$ & $30(22,40)$ \\
\hline \multicolumn{4}{|l|}{ Poultry (g/day) } \\
\hline Cluster 1/cluster 2 & $13(10,18)$ & $13(10,18)$ & $11(11,17)$ \\
\hline Cluster 3 & $13(11,19)$ & $13(11,19)$ & $13(10,19)$ \\
\hline \multicolumn{4}{|l|}{ Processed meat (g/day) } \\
\hline Cluster 1/cluster 2 & $39(28,57)$ & $38(28,56)$ & $50(33,69)$ \\
\hline Cluster 3 & $59(42,81)$ & $58(42,81)$ & $61(45,80)$ \\
\hline \multicolumn{4}{|l|}{ Eggs (g/day) } \\
\hline Cluster $1 /$ cluster 2 & $11(8,17)$ & $11(8,16)$ & $12(10,22)$ \\
\hline Cluster 3 & $13(9,20)$ & $12(8,20)$ & $14(9,20)$ \\
\hline \multicolumn{4}{|l|}{ Total dairy (g/day) } \\
\hline Cluster 1/cluster 2 & $186(122,264)$ & $188(125,267)$ & $162(105,212)$ \\
\hline Cluster 3 & $149(94,224)$ & $148(91,226)$ & $150(95,218)$ \\
\hline \multicolumn{4}{|l|}{ Milk (g/day) } \\
\hline Cluster 1/cluster 2 & $77(30,138)$ & $78(30,140)$ & $53(32,115)$ \\
\hline Cluster 3 & $47(16,100)$ & $52(16,105)$ & $44(16,87)$ \\
\hline \multicolumn{4}{|l|}{ Yogurt (g/day) } \\
\hline Cluster 1/cluster 2 & $32(14,70)$ & $33(14,71)$ & $24(13,51)$ \\
\hline Cluster 3 & $23(13,56)$ & $23(13,51)$ & $23(13,56)$ \\
\hline \multicolumn{4}{|l|}{ Cheese (g/day) } \\
\hline Cluster $1 /$ cluster 2 & $27(19,37)$ & $27(19,37)$ & $28(20,38)$ \\
\hline Cluster 3 & $26(19,37)$ & $26(20,37)$ & $26(18,36)$ \\
\hline \multicolumn{4}{|l|}{ Coffee (g/day) } \\
\hline Cluster 1/cluster 2 & $435(366,479)$ & $433(366,478)$ & $449(349,501)$ \\
\hline Cluster 3 & $438(331,483)$ & $420(303,476)$ & $456(374,499)$ \\
\hline \multicolumn{4}{|c|}{ Fruit and vegetable juice (g/day) } \\
\hline Cluster 1/cluster 2 & $45(24,115)$ & $45(24,116)$ & $32(22,86)$ \\
\hline Cluster 3 & $36(24,125)$ & $43(26,167)$ & $30(23,108)$ \\
\hline
\end{tabular}


Table 2 (continued)

\begin{tabular}{|c|c|c|c|}
\hline & Median $(25 \%, 75 \%)$ & Median $(25 \%, 75 \%)$ & Median $(25 \%, 75 \%)$ \\
\hline \multicolumn{4}{|l|}{ SSB (g/day) } \\
\hline Cluster $1 /$ cluster 2 & $6(3,16)$ & $6(3,17)$ & $5(3,9)$ \\
\hline Cluster 3 & $10(5,58)$ & $11(6,47)$ & $7(4,66)$ \\
\hline \multicolumn{4}{|l|}{ Nutrient } \\
\hline \multicolumn{4}{|l|}{ Energy intake (kJ/day) } \\
\hline Cluster 1/cluster 2 & $7657(6520,8872)$ & $7615(6509,8885)$ & $7972(6595,8772)$ \\
\hline Cluster 3 & $7821(6516,9136)$ & 8007 (6657, 9296) & $7672(6334,8810)$ \\
\hline \multicolumn{4}{|l|}{ Alcohol (g/day) } \\
\hline Cluster $1 /$ cluster 2 & $5(3,14)$ & $5(3,14)$ & $5(2,16)$ \\
\hline Cluster 3 & $6(3,17)$ & $7(3,19)$ & $5(2,14)$ \\
\hline \multicolumn{4}{|l|}{ Total fiber (g/day) } \\
\hline Cluster 1/cluster 2 & $18(14,21)$ & $17(14,21)$ & $18(16,21)$ \\
\hline Cluster 3 & $16(14,19)$ & $16(14,19)$ & $16(14,19)$ \\
\hline
\end{tabular}

Median (25th, 75th percentile)

KORA Cooperative Health Research in the Region of Augsburg, NGT normal glucose tolerance, SSB sugar-sweetened beverages, $T 2 D M$ type 2 diabetes mellitus, UDM undetected diabetes mellitus

intake of total meat, red meat, processed meat, SSB and total energy was higher and the intake of vegetables, total dairy, milk, yogurt and fruit and vegetable juice was lower in cluster 3 compared to the combined clusters 1 and 2 . In both metabotype subgroups, the intake of potatoes and coffee was higher and the intake of milk, fruit and vegetable juice and SSB was lower in individuals with UDM/prevalent T2DM compared to individuals with NGT/prediabetes. Participants with UDM/prevalent T2DM in clusters 1 and 2 showed a higher intake of total meat and total energy, whereas participants with UDM/prevalent T2DM in cluster 3 showed a lower intake of total meat and total energy compared to the participants with NGT/prediabetes of the respective metabotype subgroup.

In the total study population, intake of fruits and fiber as well as moderate alcohol consumption showed negative associations and intake of total meat, red meat, processed meat and SSB showed positive associations with UDM/ prevalent T2DM (all $p<0.05$ ) in the basic model. These results are provided in Supplemental Table 2 in the Online Resource. Table 3 displays the odds ratios (OR) and $95 \%$ confidence intervals (CI) of the fully adjusted logistic regression models for the total study population. After adjustment for the additional covariates, associations remained significant for intake of fruits (OR per increase in intake amount by 50 g/day: 0.86, 95\% CI 0.75-0.98), total meat (OR 1.50, 95\% CI 1.09-2.08), processed meat (OR 1.83, 95\% CI 1.22-2.77) and SSB (OR 1.09, 95\% CI 1.01-1.17) (all $p<0.05$ ).

The results of the fully adjusted models stratified by metabotype subgroup are presented in Table 4 (results of the basic model are shown in Supplemental Table 3 in the Online Resource). The positive associations of intake of total meat (OR 1.67, 95\% CI 1.04-2.67) and processed meat (OR 2.23, 95\% CI 1.24-4.04) with UDM/prevalent T2DM, per increase in intake amount by $50 \mathrm{~g} /$ day, remained significant in the combined clusters 1 and 2 only. In contrast, the negative association of intake of fruits (OR $0.83,95 \% \mathrm{CI}$ 0.68-0.99) and the positive association of intake of SSB (OR 1.21, 95\% CI 1.09-1.35) with UDM/prevalent T2DM, per increase in intake amount by $50 \mathrm{~g} /$ day, remained significant in cluster 3 only. Significant interaction effects with metabotype subgroups were determined for intake of eggs $(p=0.02)$ and SSB $(p=0.01)$. Analyses were not further stratified by sex due to non-significance of interaction effects $(p \geq 0.05)$ with dietary intake.

The results (ORs, 95\% CIs and $p$ values for interaction) of the sensitivity analysis with intermediate adjusted models, that means without the covariates hypertension and waist circumference, are shown in Supplemental Table 4 and Supplemental Table 5 in the Online Resource. These have not changed significantly in the total study population. In the analyses stratified by metabotype, the results were also only slightly different. However, the associations of intake of total meat and processed meat with UDM/prevalent T2DM in cluster 3 reached statistical significance. Likewise, the sensitivity analysis restricted to 762 adults aged $\geq 60$ years showed results similar to the analyses of the total study population (data not shown). 
Table 3 Fully adjusted associations between the consumption of various food items and nutrients with UDM/Prevalent T2DM in the total study population, KORA FF4 study

\begin{tabular}{lll}
\hline Food or nutrient & \multicolumn{2}{l}{ Fully adjusted model } \\
\cline { 2 - 3 } & OR & $95 \%$ CI \\
\hline Fruits (50 g/day) & $\mathbf{0 . 8 6}$ & $\mathbf{0 . 7 5 - 0 . 9 8}$ \\
Vegetables (50 g/day) & 1.17 & $0.96-1.43$ \\
Potatoes (50 g/day) & 1.16 & $0.73-1.84$ \\
Total meat (50 g/day) & $\mathbf{1 . 5 0}$ & $\mathbf{1 . 0 9}-\mathbf{2 . 0 8}$ \\
Red meat (50 g/day) & 1.01 & $0.39-2.53$ \\
Poultry (50 g/day) & 1.50 & $0.38-5.51$ \\
Processed meat (50 g/day) & $\mathbf{1 . 8 3}$ & $\mathbf{1 . 2 2}-\mathbf{2 . 7 7}$ \\
Eggs (50 g/day) & 0.85 & $0.39-1.75$ \\
Total dairy (50 g/day) & 1.00 & $0.90-1.11$ \\
Milk (50 g/day) & 0.97 & $0.85-1.10$ \\
Yogurt (50 g/day) & 1.08 & $0.86-1.33$ \\
Cheese (50 g/day) & 1.58 & $0.76-3.27$ \\
Coffee (50 g/day) & 1.02 & $0.96-1.09$ \\
Fruit and vegetable juice (50 g/day) & 0.97 & $0.87-1.07$ \\
SSB (50 g/day) & $\mathbf{1 . 0 9}$ & $\mathbf{1 . 0 1 - 1 . 1 7}$ \\
Moderate alcohol consumption ${ }^{\mathrm{a}}$ & 1.03 & $0.67-1.57$ \\
High alcohol consumption $^{\mathrm{a}}$ & 0.89 & $0.52-1.52$ \\
Total fiber (10 g/day) & 1.11 & $0.62-1.93$ \\
\hline
\end{tabular}

Logistic regression models: reference category $=\mathrm{NGT} /$ prediabetes. Fully adjusted models adjusted for age, sex, energy intake, waist circumference, family history of diabetes, physical activity, smoking, education, hypertension and metabotype. Significant results $(p<0.05)$ printed in bold

$N=1517$

CI confidence interval, KORA Cooperative Health Research in the Region of Augsburg, NGT normal glucose tolerance, $O R$ odds ratio, SSB sugar-sweetened beverages, T2DM type 2 diabetes mellitus, $U D M$ undetected diabetes mellitus

${ }^{a}$ Compared against low alcohol intake $(<5 \mathrm{~g} /$ day for men, $<2 \mathrm{~g} /$ day for women as reference category); moderate considered 5 to $<20 \mathrm{~g} /$ day for men, 2 to $<10 \mathrm{~g} /$ day for women; high considered $\geq 20 \mathrm{~g} /$ day for men, $\geq 10 \mathrm{~g} /$ day for women

\section{Discussion}

\section{Summary of main results}

In the KORA FF4 study population, a low intake of fruits and a high intake of total meat, processed meat and SSB were significantly associated with UDM/prevalent T2DM. Taking into account metabolic differences between individuals, each of these associations remained significant only in one of both metabotype subgroups. In the combined clusters 1 and 2, the intake of total meat and processed meat showed a positive association with UDM/prevalent T2DM. In cluster 3, the intake of fruits was negative and the intake of SSB was positively associated with UDM/prevalent T2DM. Despite these differences in significant associations between metabotype subgroups, only the interaction effect between intake of SSB and metabotype was significant. In addition, the association between the intake of eggs and UDM/ prevalent T2DM was also significantly different between metabotype subgroups, however, egg intake was not significantly associated with UDM/prevalent T2DM in the individual metabotype subgroups potentially caused by loss of statistical power due to stratification. Thus, further significant associations or significant differences in diet-diabetes associations between metabotypes as for example for intake of coffee ( $p$ value for interaction $=0.09$ ) and processed meat ( $p$ value for interaction $=0.11$ ) might be detectable in larger cohorts.

\section{Discussion of results regarding the existing literature on diet-diabetes associations}

In general, the associations of intakes of fruits, total meat, processed meat and SSB with UDM/prevalent T2DM that we found in the total KORA FF4 study population are in line with previous meta-analyses and review articles on the respective food groups [39-48]. However, results of a number of other studies were inconsistent $[9,10]$, and there are studies that have shown either no or only weak associations between these food groups and diabetes [49-57]. All other selected dietary intake variables were not associated with $\mathrm{UDM} /$ prevalent T2DM in our study, in contrast to some of the previous studies $[9,10,34,35]$. Our study was the first to investigate associations between diet and diabetes stratifying by metabotype, i.e., considering metabolic differences between individuals. As we identified intakes of fruits, total meat, processed meat and SSB to be significantly associated with diabetes in only one of both metabotypes, metabolic differences may partially explain conflicting results in diet-diabetes associations observed in previous studies. This holds mainly for the association between intake of SSB and diabetes, which was shown to be significantly different between both metabotype subgroups. Despite previously described age-related metabolic differences [58], the results of our sensitivity analysis restricted to older participants $\geq 60$ years remained relatively stable. Consequently, these metabotypes may be relevant for adult populations with a large age range and not only for adult populations with specific age categories.

\section{Metabotypes for the development of targeted dietary recommendations for diabetes prevention}

In the previous literature, there are numerous studies on metabotyping [16, 22, 23]. Some of these studies defined metabotypes including fasting plasma values, while a few studies classified metabotypes based on plasma parameter responsiveness to dietary interventions [17, 22, 59-62]. 
Table 4 Fully adjusted associations between the consumption of various food items and nutrients with UDM/ prevalent T2DM stratified by metabotype subgroup, KORA FF4 study

\begin{tabular}{|c|c|c|c|c|c|}
\hline \multirow[t]{2}{*}{ Food or nutrient } & \multicolumn{2}{|c|}{$\begin{array}{l}\text { Cluster 1/cluster } 2 \\
N=1217\end{array}$} & \multicolumn{2}{|c|}{$\begin{array}{l}\text { Cluster } 3 \\
N=300\end{array}$} & \multirow[t]{2}{*}{$\begin{array}{l}p \text { value } \\
\text { interaction }^{\mathrm{b}}\end{array}$} \\
\hline & OR & $95 \% \mathrm{CI}$ & OR & $95 \% \mathrm{CI}$ & \\
\hline Fruits (50 g/day) & 0.91 & $0.75-1.11$ & $\mathbf{0 . 8 3}$ & 0.68-0.99 & 0.24 \\
\hline Vegetables (50 g/day) & 1.25 & $0.94-1.64$ & 1.09 & $0.80-1.47$ & 0.63 \\
\hline Potatoes (50 g/day) & 0.82 & $0.41-1.57$ & 1.59 & $0.80-3.23$ & 0.74 \\
\hline Total meat (50 g/day) & 1.67 & $1.04-2.67$ & 1.51 & $0.95-2.41$ & 0.16 \\
\hline Red meat (50 g/day) & 0.95 & $0.20-3.92$ & 0.89 & $0.26-3.03$ & 0.49 \\
\hline Poultry (50 g/day) & 0.79 & $0.07-6.81$ & 2.29 & $0.40-13.42$ & 0.64 \\
\hline Processed meat (50 g/day) & 2.23 & $1.24-4.04$ & 1.79 & $1.00-3.26$ & 0.11 \\
\hline Eggs (50 g/day) & 1.82 & $0.65-4.73$ & 0.38 & $0.12-1.14$ & 0.02 \\
\hline Total dairy (50 g/day) & 0.97 & $0.84-1.12$ & 1.02 & $0.89-1.18$ & 0.83 \\
\hline Milk (50 g/day) & 0.93 & $0.76-1.10$ & 1.00 & $0.83-1.21$ & 0.70 \\
\hline Yogurt (50 g/day) & 1.05 & $0.75-1.41$ & 1.14 & $0.83-1.59$ & 0.71 \\
\hline Cheese (50 g/day) & 2.44 & $0.87-6.67$ & 1.02 & $0.36-2.91$ & 0.13 \\
\hline Coffee (50 g/day) & 0.97 & $0.88-1.07$ & 1.08 & $0.98-1.18$ & 0.09 \\
\hline Fruit and vegetable juice ( $50 \mathrm{~g} /$ day $)$ & 0.98 & $0.83-1.13$ & 0.97 & $0.84-1.12$ & 0.53 \\
\hline $\operatorname{SSB}(50 \mathrm{~g} /$ day $)$ & 0.92 & $0.73-1.08$ & 1.21 & $1.09-1.35$ & 0.01 \\
\hline Moderate alcohol consumption ${ }^{\mathrm{a}}$ & 0.97 & $0.53-1.76$ & 1.05 & $0.55-1.98$ & 0.75 \\
\hline High alcohol consumption $^{\mathrm{a}}$ & 0.84 & $0.39-1.78$ & 0.81 & $0.37-1.77$ & \\
\hline Total fiber (10 g/day) & 1.44 & $0.65-3.08$ & 0.87 & $0.36-2.09$ & 0.29 \\
\hline
\end{tabular}

Logistic regression models: reference category = NGT/prediabetes. Fully adjusted models adjusted for age, sex, energy intake, waist circumference, family history of diabetes, physical activity, smoking, education and hypertension. Significant results $(p<0.05)$ printed in bold

$N=1517$

CI confidence interval, KORA Cooperative Health Research in the Region of Augsburg, NGT normal glucose tolerance, $O R$ odds ratio, SSB sugar-sweetened beverages, T2DM type 2 diabetes mellitus, UDM undetected diabetes mellitus

${ }^{a}$ Compared against low alcohol intake ( $<5 \mathrm{~g} /$ day for men, $<2 \mathrm{~g} /$ day for women as reference category); moderate considered 5 to $<20 \mathrm{~g} /$ day for men, 2 to $<10 \mathrm{~g} /$ day for women; high considered $\geq 20 \mathrm{~g} /$ day for men, $\geq 10 \mathrm{~g} /$ day for women

${ }^{\mathrm{b}} p$ value of likelihood ratio test for the comparison of models with and without the interaction term of metabotype and the respective food or nutrient
Fewer studies tested metabotype subgroups for a differential responsiveness to dietary intervention in a disease-specific manner [63-65]. For example, O’Sullivan et al. [63] identified a vitamin D-responsive metabotype subgroup concerning markers of the metabolic syndrome, Moazzami et al. [64] found subgroups of individuals with different insulin response after an intervention with breads, and VázquezFresno [65] detected a responsive metabotype subgroup of cardiovascular risk patients to red wine polyphenols. In addition, O'Donovan et al. were the only ones developing dietary recommendations based on metabotype subgroups which was done using a decision tree approach [66, 67]. Thus to date, metabotypes have been rarely used for the development and establishment of targeted dietary recommendations for disease prevention. Further research should identify discrete differences between metabotype subgroups in the context of diet-disease relationships. By assigning individuals to metabotype subgroups, targeted dietary recommendations in disease prevention may be implemented in whole populations.

Concerning the metabotypes identified in KORA FF4, diabetes prevention may be especially relevant for cluster 3, defining an unfavorable metabotype concerning metabolic characteristics. In detail, this cluster showed the highest median concentrations of glucose and glycated hemoglobin, which are used in the diagnosis of prediabetes and prevalent T2DM [68]. Consequently, there were high numbers of individuals with prediabetes, UDM and prevalent T2DM in this cluster. However, clusters 1 and 2 defining a rather beneficial metabotype could also benefit from targeted prevention due to the high prevalence of prediabetes, which is a strong risk factor for the development of T2DM [69]. Other known risk factors for diabetes such as age, obesity, physical inactivity, family history of diabetes and hypertension were most frequent in cluster 3 [1, 68, 70]. In addition, low education as seen in cluster 3 was linked to poor health [71]. 
The lowest percentage of current smokers and simultaneous highest percentage of ex-smokers in cluster 3 indicated smoking cessation due to the high diabetes prevalence in this cluster, as smoking is as well a strong risk factor for diabetes $[1,70]$. When assessing dietary intake in our metabotype subgroups, individuals in cluster 3 showed a higher intake of total energy, total meat, red meat, processed meat and SSB than individuals in clusters 1 and 2. Simultaneously, individuals in cluster 3 consumed lower amounts of vegetables, total dairy, milk, yogurt and fruit and vegetable juice compared to individuals in clusters 1 and 2 . This dietary pattern was shown to be associated with increased risk for diabetes $[9,10]$. As targeted dietary advice may be more effective than general recommendations [11, 14, 16, 24, 25], the development of strategies for change in dietary behavior on the metabotype subgroup level, especially for the 'highrisk' cluster 3, could improve the prevention of diabetes.

\section{Strengths and limitations}

One of the strengths of the study is the fact that associations between diet and diabetes were investigated in a large population-based study, allowing us to perform stratified analyses by metabotype with sufficient sample sizes. Due to the lack of a uniform definition of the term 'metabotype', metabotyping was performed in KORA FF4 analogous to Riedl et al. [23] in KORA F4 to get comprehensive metabotypes based on a broad range of parameters [22]. However, only 16 of the 34 biochemical and anthropometric parameters originally used in F4, were available in FF4. Repeating the identification of metabotypes in F4 with the reduced set of 16 parameters also available in FF4 and comparing to the originally identified metabotypes in F4 based on 34 parameters, revealed a similar allocation of individuals to the clusters ( 1513 of 1729 individuals or $87.5 \%$ of participants). In addition, the newly defined metabotypes in FF4 based on the 16 parameters showed a good distinction of demographic and metabolic characteristics. Consequently, we assume to have identified metabotypes in KORA FF4 that are still comprehensive despite the reduced set of biochemical markers and we assume that these metabotypes were appropriate to consider metabolic differences in diet-diabetes associations. Another strength is the availability of extensive dietary data assessed by food frequency questionnaire and up to three 24-h food lists, which enabled the investigation of a large number of food items and their association with diabetes. However, as with all dietary assessment methods, misreporting cannot be ruled out. Further strengths include the assessment of diabetes by either a physician-validated diagnosis or an OGTT, and the availability of a large number of confounders for adjustment. Limitations of the study include the fact that a large proportion of the original S4 participants (1982 of 4261 individuals) did not participate again in the second follow-up KORA FF4 study due to death, refusal and loss to follow-up, what could have biased our results. Furthermore, due to the cross-sectional study design, no causal relationships between dietary factors and diabetes could be established and longitudinal or intervention studies considering metabolic differences are needed. In addition, samples sizes, dietary intake amounts and the diabetes prevalence varied considerably between metabotype subgroups, which could have influenced our results.

\section{Conclusions}

Our cross-sectional results show differences in associations with diabetes for intake of fruits, total meat, processed meat, and especially for intake of SSB between distinct metabotype subgroups. This suggests an influence of metabolic characteristics on diet-diabetes associations, which may help to explain the inconsistent results of previous studies. Further, prospective and intervention studies are needed to further elucidate the causal relationships between diet and diabetes within specific metabolic subgroups. These results may enable the development of targeted dietary recommendations on the metabotype subgroup level in diabetes prevention.

Acknowledgements The Cooperative Health Research in the Region of Augsburg (KORA) studies were initiated and financed by the Helmholtz Zentrum München-German Research Center for Environmental Health, which is funded by the German Federal Ministry of Education and Research (BMBF) and by the State of Bavaria. Furthermore, KORA research was supported within the Munich Center of Health Sciences (MC-Health), Ludwig-Maximilians-Universität, as part of LMUinnovativ. The German Diabetes Center was supported by the Ministry of Culture and Science of the State of North Rhine-Westphalia and the German Federal Ministry of Health. This study was supported in part by a grant from the German Federal Ministry of Education and Research (BMBF) to the German Center for Diabetes Research (DZD). The preparation of this paper was supported by the enable Cluster and is catalogued by the enable Steering Committee as enable 029 (http:// enable-cluster.de). This work was funded by a grant of the German Ministry for Education and Research (BMBF) FK 01EA1409E.

Author contributions AR: conceived and conducted the data analyses, interpreted the data, and wrote the manuscript; NW, CG: contributed to data analyses and interpretation, and revised the manuscript; CM, AP, WR, WK, KS, ASQ, BT, CH: were involved in the study organization, provided data, and reviewed the manuscript; $\mathrm{HD}, \mathrm{HH}$ : contributed to data interpretation and revised the manuscript; JL: conceived and designed the data analyses, contributed to data analyses and interpretation, and revised the manuscript; All authors have read and approved the final manuscript.

\section{Compliance with ethical standards}

Conflict of interest The authors declare that they have no conflict of interest. 
Open Access This article is distributed under the terms of the Creative Commons Attribution 4.0 International License (http://creativeco mmons.org/licenses/by/4.0/), which permits unrestricted use, distribution, and reproduction in any medium, provided you give appropriate credit to the original author(s) and the source, provide a link to the Creative Commons license, and indicate if changes were made.

\section{References}

1. World Health Organization (2016) Global report on diabetes. World Health Organization, Geneva

2. Wild S, Roglic G, Green A, Sicree R, King H (2004) Global prevalence of diabetes: estimates for the year 2000 and projections for 2030. Diabetes Care 27(5):1047-1053

3. Goffrier B, Schulz M, Bätzing-Feigenbaum J (2017) Administrative Prävalenzen und Inzidenzen des Diabetes mellitus von 2009 bis 2015. Zentralinstitut für die kassenärztliche Versorgung in Deutschland (Zi). Versorgungsatlas-Bericht Nr. 17/03. Berlin. https://doi.org/10.20364/va-17.03. http://www.versorgungsatla s.de/themen/alle-analysen-nach-datum-sortiert/?tab $=6 \&$ uid $=79$. Accessed 30 Aug 2018

4. Meisinger C, Strassburger K, Heier M, Thorand B, Baumeister SE, Giani G, Rathmann W (2010) Prevalence of undiagnosed diabetes and impaired glucose regulation in 35-59-year-old individuals in Southern Germany: the KORA F4 Study. Diabet Med 27(3):360-362. https://doi.org/10.1111/j.1464-5491.2009.02905 .x

5. Rathmann W, Haastert B, Icks A, Löwel H, Meisinger C, Holle R, Giani G (2003) High prevalence of undiagnosed diabetes mellitus in Southern Germany: target populations for efficient screening. The KORA survey 2000. Diabetologia 46(2):182-189. https://doi. org/10.1007/s00125-002-1025-0

6. Walker KZ, O’Dea K, Gomez M, Girgis S, Colagiuri R (2010) Diet and exercise in the prevention of diabetes. J Hum Nutr Diet 23(4):344-352. https://doi.org/10.1111/j.1365-277X.2010.01061 . $\mathrm{x}$

7. Bazzano LA, Serdula M, Liu S (2005) Prevention of type 2 diabetes by diet and lifestyle modification. J Am Coll Nutr 24(5):310-319

8. Thomas GN, Jiang CQ, Taheri S, Xiao ZH, Tomlinson B, Cheung BM, Lam TH, Barnett AH, Cheng KK (2010) A systematic review of lifestyle modification and glucose intolerance in the prevention of type 2 diabetes. Curr Diabetes Rev 6(6):378-387

9. Schwingshackl L, Hoffmann G, Lampousi AM, Knüppel S, Iqbal K, Schwedhelm C, Bechthold A, Schlesinger S, Boeing H (2017) Food groups and risk of type 2 diabetes mellitus: a systematic review and meta-analysis of prospective studies. Eur J Epidemiol 32(5):363-375. https://doi.org/10.1007/s10654-017-0246-y

10. Xi P, Liu RH (2016) Whole food approach for type 2 diabetes prevention. Mol Nutr Food Res 60(8):1819-1836. https://doi. org/10.1002/mnfr.201500963

11. Holmes E, Wilson ID, Nicholson JK (2008) Metabolic phenotyping in health and disease. Cell 134(5):714-717. https://doi. org/10.1016/j.cell.2008.08.026

12. Nicholson JK (2006) Global systems biology, personalized medicine and molecular epidemiology. Mol Syst Biol 2:52. https://doi. org/10.1038/msb4100095

13. Beger RD, Dunn W, Schmidt MA, Gross SS, Kirwan JA, Cascante M, Brennan L, Wishart DS, Oresic M, Hankemeier T, Broadhurst DI, Lane AN, Suhre K, Kastenmüller G, Sumner SJ, Thiele I, Fiehn O, Kaddurah-Daouk R, for "Precision Medicine and Pharmacometabolomics Task Group"-Metabolomics Society Initiative (2016) Metabolomics enables precision medicine: "A White
Paper, Community Perspective”. Metabolomics 12(10):149. https ://doi.org/10.1007/s11306-016-1094-6

14. de Roos B (2013) Personalised nutrition: ready for practice? Proc Nutr Soc 72(1):48-52. https://doi.org/10.1017/S00296651120028 44

15. Nicholson JK, Holmes E (2006) Global systems biology and personalized healthcare solutions. Discov Med 6(32):63-70

16. O'Donovan CB, Walsh MC, Gibney MJ, Gibney ER, Brennan L (2016) Can metabotyping help deliver the promise of personalised nutrition? Proc Nutr Soc 75(1):106-114. https://doi.org/10.1017/ S0029665115002347

17. Morris C, O'Grada C, Ryan M, Roche HM, Gibney MJ, Gibney ER, Brennan L (2013) Identification of differential responses to an oral glucose tolerance test in healthy adults. PLoS One 8(8):e72890. https://doi.org/10.1371/journal.pone.0072890

18. Nicholson JK, Holmes E, Kinross JM, Darzi AW, Takats Z, Lindon JC (2012) Metabolic phenotyping in clinical and surgical environments. Nature 491(7424):384-392. https://doi.org/10.1038/natur e11708

19. Kaput J (2008) Nutrigenomics research for personalized nutrition and medicine. Curr Opin Biotechnol 19(2):110-120. https://doi. org/10.1016/j.copbio.2008.02.005

20. Brennan L (2008) Session 2: personalised nutrition. Metabolomic applications in nutritional research. Proc Nutr Soc 67(4):404-408. https://doi.org/10.1017/s0029665108008719

21. Brennan L (2017) Use of metabotyping for optimal nutrition. Curr Opin Biotechnol 44:35-38. https://doi.org/10.1016/j.copbi o.2016.10.008

22. Riedl A, Gieger C, Hauner H, Daniel H, Linseisen J (2017) Metabotyping and its application in targeted nutrition: an overview. Br J Nutr 117(12):1631-1644. https://doi.org/10.1017/ S0007114517001611

23. Riedl A, Wawro N, Gieger C, Meisinger C, Peters A, Roden M, Kronenberg F, Herder C, Rathmann W, Völzke H, Reincke M, Koenig W, Wallaschofski H, Hauner H, Daniel H, Linseisen J (2018) Identification of comprehensive metabotypes associated with cardiometabolic diseases in the population-based KORA study. Mol Nutr Food Res 62(16):e1800117. https://doi. org/10.1002/mnfr.201800117

24. Celis-Morales C, Livingstone KM, Marsaux CF, Macready AL, Fallaize R, O'Donovan CB, Woolhead C, Forster H, Walsh MC, Navas-Carretero S, San-Cristobal R, Tsirigoti L, Lambrinou CP, Mavrogianni C, Moschonis G, Kolossa S, Hallmann J, Godlewska M, Surwillo A, Traczyk I, Drevon CA, Bouwman J, van Ommen B, Grimaldi K, Parnell LD, Matthews JN, Manios Y, Daniel H, Martinez JA, Lovegrove JA, Gibney ER, Brennan L, Saris WH, Gibney M, Mathers JC, Food4Me Study (2017) Effect of personalized nutrition on health-related behaviour change: evidence from the Food4me European randomized controlled trial. Int J Epidemiol 46(2):578-588

25. Livingstone KM, Celis-Morales C, Navas-Carretero S, SanCristobal R, Macready AL, Fallaize R, Forster H, Woolhead C, O’Donovan CB, Marsaux CF, Kolossa S, Tsirigoti L, Lambrinou CP, Moschonis G, Godlewska M, Surwillo A, Drevon CA, Manios Y, Traczyk I, Gibney ER, Brennan L, Walsh MC, Lovegrove JA, Saris WH, Daniel H, Gibney M, Martinez JA, Mathers JC, Food4Me Study (2016) Effect of an Internet-based, personalized nutrition randomized trial on dietary changes associated with the Mediterranean diet: the Food4Me Study. Am J Clin Nutr 104(2):288-297. https://doi.org/10.3945/ajcn.115.129049

26. Holle R, Happich M, Löwel H, Wichmann HE, MONICA/KORA Study Group (2005) KORA - a research platform for population based health research. Gesundheitswesen 67(Suppl 1):S19-S25. https://doi.org/10.1055/s-2005-858235

27. Holle R, Hochadel M, Reitmeir P, Meisinger C, Wichmann HE, KORA Group (2006) Prolonged recruitment efforts in health 
surveys: effects on response, costs, and potential bias. Epidemiology 17(6):639-643. https://doi.org/10.1097/01.ede.0000239731 $.86975 .7 \mathrm{f}$

28. American Diabetes Association (2011) Diagnosis and classification of diabetes mellitus. Diabetes Care 34(Suppl 1):S62-S69. https://doi.org/10.2337/dc11-S062

29. Kowall B, Rathmann W, Stang A, Bongaerts B, Kuss O, Herder C, Roden M, Quante A, Holle R, Huth C, Peters A, Meisinger C (2017) Perceived risk of diabetes seriously underestimates actual diabetes risk: the KORA FF4 study. PLoS One 12(1):e0171152. https://doi.org/10.1371/journal.pone.0171152

30. Freese J, Feller S, Harttig U, Kleiser C, Linseisen J, Fischer B, Leitzmann MF, Six-Merker J, Michels KB, Nimptsch K, Steinbrecher A, Pischon T, Heuer T, Hoffmann I, Jacobs G, Boeing H, Nöthlings U (2014) Development and evaluation of a short 24-h food list as part of a blended dietary assessment strategy in largescale cohort studies. Eur J Clin Nutr 68(3):324-329. https://doi. org/10.1038/ejcn.2013.274

31. Tooze JA, Kipnis V, Buckman DW, Carroll RJ, Freedman LS, Guenther PM, Krebs-Smith SM, Subar AF, Dodd KW (2010) A mixed-effects model approach for estimating the distribution of usual intake of nutrients: the NCI method. Stat Med 29(27):28572868. https://doi.org/10.1002/sim.4063

32. Haubrock J, Nöthlings U, Volatier JL, Dekkers A, Ocké M, Harttig U, Illner AK, Knüppel S, Andersen LF, Boeing H, European Food Consumption Validation Consortium (2011) Estimating usual food intake distributions by using the multiple source method in the EPIC-Potsdam Calibration Study. J Nutr 141(5):914-920. https://doi.org/10.3945/jn.109.120394

33. Slimani N, Deharveng G, Charrondière RU, van Kappel AL, Ocké MC, Welch A, Lagiou A, van Liere M, Agudo A, Pala V, Brandstetter B, Andren C, Stripp C, van Staveren WA, Riboli E (1999) Structure of the standardized computerized 24-h diet recall interview used as reference method in the 22 centers participating in the EPIC project. European Prospective Investigation into Cancer and Nutrition. Comput Methods Programs Biomed 58(3):251-266

34. Mozaffarian D (2016) Dietary and policy priorities for cardiovascular disease, diabetes, and obesity: a comprehensive review. Circulation 133(2):187-225. https://doi.org/10.1161/CIRCULATIO NAHA.115.018585

35. InterAct Consortium (2015) Dietary fibre and incidence of type 2 diabetes in eight European countries: the EPIC-InterAct Study and a meta-analysis of prospective studies. Diabetologia 58(7):13941408. https://doi.org/10.1007/s00125-015-3585-9

36. van Buuren S, Groothuis-Oudshoorn K (2011) mice: multivariate imputation by chained equations in R. J Stat Softw 45(3):1-67

37. Basagana X, Barrera-Gómez J, Benet M, Antó JM, Garcia-Aymerich J (2013) A framework for multiple imputation in cluster analysis. Am J Epidemiol 177(7):718-725. https://doi.org/10.1093/aje/ kws 289

38. Deutsche Gesellschaft für Ernährung (DGE), Österreichische Gesellschaft für Ernährung (ÖGE), Schweizerische Gesellschaft für Ernährungsforschung (SGE), Schweizerische Vereinigung für Ernährung (SVE) (2008) Referenzwerte für die Nährstoffzufuhr 1. Auflage. Neuer Umschau Buchverlag, Neustadt an der Weinstraße

39. Li M, Fan Y, Zhang X, Hou W, Tang Z (2014) Fruit and vegetable intake and risk of type 2 diabetes mellitus: meta-analysis of prospective cohort studies. BMJ Open 4(11):e005497. https://doi. org/10.1136/bmjopen-2014-005497

40. Wang PY, Fang JC, Gao ZH, Zhang C, Xie SY (2016) Higher intake of fruits, vegetables or their fiber reduces the risk of type 2 diabetes: a meta-analysis. J Diabetes Investig 7(1):56-69. https ://doi.org/10.1111/jdi.12376

41. Li S, Miao S, Huang Y, Liu Z, Tian H, Yin X, Tang W, Steffen LM, Xi B (2015) Fruit intake decreases risk of incident type 2 diabetes: an updated meta-analysis. Endocrine 48(2):454-460. https://doi.org/10.1007/s12020-014-0351-6

42. Aune D, Ursin G, Veierod MB (2009) Meat consumption and the risk of type 2 diabetes: a systematic review and meta-analysis of cohort studies. Diabetologia 52(11):2277-2287. https://doi. org/10.1007/s00125-009-1481-x

43. Micha R, Wallace SK, Mozaffarian D (2010) Red and processed meat consumption and risk of incident coronary heart disease, stroke, and diabetes mellitus: a systematic review and meta-analysis. Circulation 121(21):2271-2283. https://doi.org/10.1161/ CIRCULATIONAHA.109.924977

44. Feskens EJ, Sluik D, van Woudenbergh GJ (2013) Meat consumption, diabetes, and its complications. Curr Diabetes Rep 13(2):298-306. https://doi.org/10.1007/s11892-013-0365-0

45. Ley SH, Hamdy O, Mohan V, Hu FB (2014) Prevention and management of type 2 diabetes: dietary components and nutritional strategies. Lancet 383(9933):1999-2007. https://doi.org/10.1016/ S0140-6736(14)60613-9

46. Imamura F, O'Connor L, Ye Z, Mursu J, Hayashino Y, Bhupathiraju SN, Forouhi NG (2015) Consumption of sugar sweetened beverages, artificially sweetened beverages, and fruit juice and incidence of type 2 diabetes: systematic review, meta-analysis, and estimation of population attributable fraction. BMJ 351:h3576. https://doi.org/10.1136/bmj.h3576

47. InterAct Consortium, Romaguera $D$, Norat $T$, Wark PA, Vergnaud AC, Schulze MB, van Woudenbergh GJ, Drogan D, Amiano P, Molina-Montes E, Sánchez MJ, Balkau B, Barricarte A, Beulens JW, Clavel-Chapelon F, Crispim SP, Fagherazzi G, Franks PW, Grote VA, Huybrechts I, Kaaks R, Key TJ, Khaw KT, Nilsson P, Overvad K, Palli D, Panico S, Quirós JR, Rolandsson O, Sacerdote C, Sieri S, Slimani N, Spijkerman AM, Tjonneland A, Tormo MJ, Tumino R, van den Berg SW, Wermeling PR, Zamara-Ros R, Feskens EJ, Langenberg C, Sharp SJ, Forouhi NG, Riboli E, Wareham NJ (2013) Consumption of sweet beverages and type 2 diabetes incidence in European adults: results from EPIC-InterAct. Diabetologia 56(7):1520-1530. https://doi.org/10.1007/ s00125-013-2899-8

48. Malik VS, Popkin BM, Bray GA, Després JP, Willett WC, Hu FB (2010) Sugar-sweetened beverages and risk of metabolic syndrome and type 2 diabetes: a meta-analysis. Diabetes Care 33(11):2477-2483. https://doi.org/10.2337/dc10-1079

49. Cooper AJ, Forouhi NG, Ye Z, Buijsse B, Arriola L, Balkau B, Barricarte A, Beulens JW, Boeing H, Büchner FL, Dahm CC, de Lauzon-Guillain B, Fagherazzi G, Franks PW, Gonzalez C, Grioni S, Kaaks R, Key TJ, Masala G, Navarro C, Nilsson P, Overvad K, Panico S, Ramón Quirós J, Rolandsson O, Roswall N, Sacerdote C, Sánchez MJ, Slimani N, Sluijs I, Spijkerman AM, Teucher B, Tjonneland A, Tumino R, Sharp SJ, Langenberg C, Feskens EJ, Riboli E, Wareham NJ, InterAct Consortium (2012) Fruit and vegetable intake and type 2 diabetes: EPIC-InterAct prospective study and meta-analysis. Eur J Clin Nutr 66(10):1082-1092. https ://doi.org/10.1038/ejen.2012.85

50. Hamer M, Chida Y (2007) Intake of fruit, vegetables, and antioxidants and risk of type 2 diabetes: systematic review and metaanalysis. J Hypertens 25(12):2361-2369. https://doi.org/10.1097/ HJH.0b013e3282efc214

51. Carter P, Gray LJ, Troughton J, Khunti K, Davies MJ (2010) Fruit and vegetable intake and incidence of type 2 diabetes mellitus: systematic review and meta-analysis. BMJ 341:c4229. https://doi. org/10.1136/bmj.c4229

52. Villegas R, Shu XO, Gao YT, Yang G, Cai H, Li H, Zheng W (2006) The association of meat intake and the risk of type 2 diabetes may be modified by body weight. Int J Med Sci 3(4):152-159

53. Montonen J, Järvinen R, Heliövaara M, Reunanen A, Aromaa A, Knekt P (2005) Food consumption and the incidence of type 
II diabetes mellitus. Eur J Clin Nutr 59(3):441-448. https://doi. org/10.1038/sj.ejen.1602094

54. Hodge AM, English DR, O’Dea K, Giles GG (2007) Dietary patterns and diabetes incidence in the Melbourne Collaborative Cohort Study. Am J Epidemiol 165(6):603-610. https://doi. org/10.1093/aje/kwk061

55. Montonen J, Järvinen R, Knekt P, Heliövaara M, Reunanen A (2007) Consumption of sweetened beverages and intakes of fructose and glucose predict type 2 diabetes occurrence. J Nutr 137(6):1447-1454. https://doi.org/10.1093/jn/137.6.1447

56. Paynter NP, Yeh HC, Voutilainen S, Schmidt MI, Heiss G, Folsom AR, Brancati FL, Kao WH (2006) Coffee and sweetened beverage consumption and the risk of type 2 diabetes mellitus: the atherosclerosis risk in communities study. Am J Epidemiol 164(11):1075-1084. https://doi.org/10.1093/aje/kwj323

57. Nettleton JA, Lutsey PL, Wang Y, Lima JA, Michos ED, Jacobs DR Jr (2009) Diet soda intake and risk of incident metabolic syndrome and type 2 diabetes in the Multi-Ethnic Study of Atherosclerosis (MESA). Diabetes Care 32(4):688-694. https://doi. org/10.2337/dc08-1799

58. Chaleckis R, Murakami I, Takada J, Kondoh H, Yanagida M (2016) Individual variability in human blood metabolites identifies age-related differences. Proc Natl Acad Sci USA 113(16):42524259. https://doi.org/10.1073/pnas.1603023113

59. Krishnan S, Newman JW, Hembrooke TA, Keim NL (2012) Variation in metabolic responses to meal challenges differing in glycemic index in healthy women: is it meaningful? Nutr Metab (Lond) 9:26. https://doi.org/10.1186/1743-7075-9-26

60. Wang TT, Edwards AJ, Clevidence BA (2013) Strong and weak plasma response to dietary carotenoids identified by cluster analysis and linked to beta-carotene $15,15^{\prime}$-monooxygenase 1 single nucleotide polymorphisms. J Nutr Biochem 24(8):1538-1546. https://doi.org/10.1016/j.jnutbio.2013.01.001

61. Bouwman J, Vogels JT, Wopereis S, Rubingh CM, Bijlsma S, van Ommen B (2012) Visualization and identification of health space, based on personalized molecular phenotype and treatment response to relevant underlying biological processes. BMC Med Genomics 5:1. https://doi.org/10.1186/1755-8794-5-1

62. Fiamoncini J, Rundle M, Gibbons H, Thomas EL, GeillingerKästle K, Bunzel D, Trezzi JP, Kiselova-Kaneva Y, Wopereis S, Wahrheit J, Kulling SE, Hiller K, Sonntag D, Ivanova D, van Ommen B, Frost G, Brennan L, Bell J, Daniel H (2018) Plasma metabolome analysis identifies distinct human metabotypes in the postprandial state with different susceptibility to weight loss-mediated metabolic improvements. FASEB J. https://doi. org/10.1096/fj.201800330r

63. O’Sullivan A, Gibney MJ, Connor AO, Mion B, Kaluskar S, Cashman KD, Flynn A, Shanahan F, Brennan L (2011) Biochemical and metabolomic phenotyping in the identification of a vitamin D responsive metabotype for markers of the metabolic syndrome. Mol Nutr Food Res 55(5):679-690. https://doi.org/10.1002/ mnfr.201000458

64. Moazzami AA, Shrestha A, Morrison DA, Poutanen K, Mykkänen $\mathrm{H}$ (2014) Metabolomics reveals differences in postprandial responses to breads and fasting metabolic characteristics associated with postprandial insulin demand in postmenopausal women. J Nutr 144(6):807-814. https://doi.org/10.3945/jn.113.188912

65. Vázquez-Fresno R, Llorach R, Perera A, Mandal R, Feliz M, Tinahones FJ, Wishart DS, Andres-Lacueva C (2016) Clinical phenotype clustering in cardiovascular risk patients for the identification of responsive metabotypes after red wine polyphenol intake. J Nutr Biochem 28:114-120. https://doi.org/10.1016/j. jnutbio.2015.10.002

66. O'Donovan CB, Walsh MC, Nugent AP, McNulty B, Walton J, Flynn A, Gibney MJ, Gibney ER, Brennan L (2015) Use of metabotyping for the delivery of personalised nutrition. Mol Nutr Food Res 59(3):377-385. https://doi.org/10.1002/mnfr.201400591

67. O'Donovan CB, Walsh MC, Woolhead C, Forster H, CelisMorales C, Fallaize R, Macready AL, Marsaux CFM, NavasCarretero S, Rodrigo San-Cristobal S, Kolossa S, Tsirigoti L, Mvrogianni C, Lambrinou CP, Moschonis G, Godlewska M, Surwillo A, Traczyk I, Drevon CA, Daniel H, Manios Y, Martinez JA, Saris WHM, Lovegrove JA, Mathers JC, Gibney MJ, Gibney ER, Brennan L (2017) Metabotyping for the development of tailored dietary advice solutions in a European population: the Food $4 \mathrm{Me}$ study. Br J Nutr 118(8):561-569. https://doi.org/10.1017/S0007 114517002069

68. Genuth S, Alberti KG, Bennett P, Buse J, Defronzo R, Kahn R, Kitzmiller J, Knowler WC, Lebovitz H, Lernmark A, Nathan D, Palmer J, Rizza R, Saudek C, Shaw J, Steffes M, Stern M, Tuomilehto J, Zimmet P, Expert Committee on the Diagnosis and Classification of Diabetes Mellitus (2003) Follow-up report on the diagnosis of diabetes mellitus. Diabetes Care 26(11):3160-3167

69. Buysschaert M, Bergman M (2011) Definition of prediabetes. Med Clin N Am 95(2):289-297, vii. https://doi.org/10.1016/j. mena.2010.11.002

70. Mühlenbruch K, Ludwig T, Jeppesen C, Joost HG, Rathmann W, Meisinger C, Peters A, Boeing H, Thorand B, Schulze MB (2014) Update of the German Diabetes Risk Score and external validation in the German MONICA/KORA study. Diabetes Res Clin Pract 104(3):459-466. https://doi.org/10.1016/j.diabres.2014.03.013

71. World Health Organization (2018) The determinants of health. World Health Organization, Geneva. http://www.who.int/hia/evide nce/doh/en/. Accessed 30 Aug 2018

\section{Affiliations}

\section{Anna Riedl ${ }^{1,2,3} \cdot$ Nina Wawro ${ }^{1,2,3} \cdot$ Christian Gieger $^{3,4,5} \cdot$ Christa Meisinger $^{1,2,3,4} \cdot$ Annette Peters 3,4 . Wolfgang Rathmann ${ }^{3,6}$. Wolfgang Koenig ${ }^{7,8,9} \cdot$ Konstantin Strauch $^{10,11} \cdot$ Anne S. Quante ${ }^{10,11,12}$ - Barbara Thorand ${ }^{3,4}$. Cornelia Huth $^{3,4} \cdot$ Hannelore Daniel $^{13} \cdot$ Hans Hauner $^{14,15,16} \cdot$ Jakob Linseisen ${ }^{1,2,15}$}

1 Independent Research Group Clinical Epidemiology, Helmholtz Zentrum München, German Research Center for Environmental Health (GmbH), Ingolstädter Landstr. 1, 85764 Neuherberg, Germany

2 Chair of Epidemiology, Ludwig-Maximilians-Universität München, at UNIKA-T (Universitäres Zentrum für
Gesundheitswissenschaften am Klinikum Augsburg), Neusässer Str. 47, 86156 Augsburg, Germany

3 German Center for Diabetes Research (DZD e.V.), Ingolstädter Landstr. 1, 85764 Neuherberg, Germany

4 Institute of Epidemiology, Helmholtz Zentrum München, German Research Center for Environmental Health $(\mathrm{GmbH})$, Ingolstädter Landstr. 1, 85764 Neuherberg, Germany 
5 Research Unit of Molecular Epidemiology, Helmholtz Zentrum München, German Research Center for Environmental Health $(\mathrm{GmbH})$, Ingolstädter Landstr. 1, 85764 Neuherberg, Germany

6 Institute for Biometrics and Epidemiology, German Diabetes Center, Leibniz Center for Diabetes Research at Heinrich Heine University Düsseldorf, Auf'm Hennekamp 65, 40225 Düsseldorf, Germany

7 DZHK (German Centre for Cardiovascular Research), Partner Site Munich Heart Alliance, Pettenkoferstr. 8a and 9, 80336 Munich, Germany

8 Deutsches Herzzentrum München, Technische Universität München, Lazarettstr. 36, 80636 Munich, Germany

9 Department of Internal Medicine II-Cardiology, University of Ulm Medical Center, Albert-Einstein-Allee 23, 89081 Ulm, Germany

10 Institute of Genetic Epidemiology, Helmholtz Zentrum München, German Research Center for Environmental Health $(\mathrm{GmbH})$, Ingolstädter Landstr. 1, 85764 Neuherberg, Germany
11 Chair of Genetic Epidemiology, IBE, Faculty of Medicine, Ludwig-Maximilians-Universität München, Marchioninistr. 15, 81377 Munich, Germany

12 Department of Gynecology and Obstetrics, University Hospital rechts der Isar, Technical University Munich, Ismaninger Str. 22, 81675 Munich, Germany

13 Chair of Nutritional Physiology, Technical University of Munich, Gregor-Mendel-Str. 2, 85354 Freising-Weihenstephan, Germany

14 Else Kröner-Fresenius Centre for Nutritional Medicine, Technical University of Munich, Gregor-Mendel-Str. 2, 85354 Freising-Weihenstephan, Germany

15 ZIEL, Institute for Food and Health, Technical University of Munich, Weihenstephaner Berg 1, 85354 Freising-Weihenstephan, Germany

16 Institute of Nutritional Medicine, University Hospital rechts der Isar, Technical University of Munich, Uptown München Campus D, Georg-Brauchle-Ring 60/62, 80992 Munich, Germany 